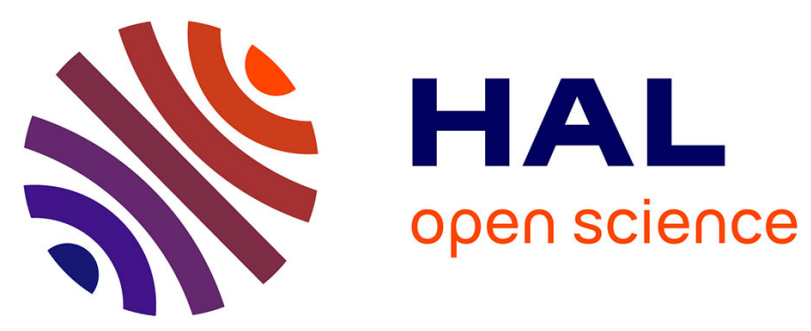

\title{
Midterm Results with the Open Chimney Technique during Endovascular Aneurysm Repair
}

Eric Ducasse, Caroline Caradu, Coline Brochier, Dominique Midy, Xavier Bérard, Mathieu Poirier, Nicolas Ottaviani

\section{- To cite this version:}

Eric Ducasse, Caroline Caradu, Coline Brochier, Dominique Midy, Xavier Bérard, et al.. Midterm Results with the Open Chimney Technique during Endovascular Aneurysm Repair. JVIR: Journal of Vascular and Interventional Radiology, 2019, 30, pp.511 - 520.e1. 10.1016/j.jvir.2018.09.013 . hal03486230

\section{HAL Id: hal-03486230 \\ https://hal.science/hal-03486230}

Submitted on 20 Dec 2021

HAL is a multi-disciplinary open access archive for the deposit and dissemination of scientific research documents, whether they are published or not. The documents may come from teaching and research institutions in France or abroad, or from public or private research centers.
L'archive ouverte pluridisciplinaire HAL, est destinée au dépôt et à la diffusion de documents scientifiques de niveau recherche, publiés ou non, émanant des établissements d'enseignement et de recherche français ou étrangers, des laboratoires publics ou privés.

\section{(ㄷ)(1) $\$$}

Distributed under a Creative Commons Attribution - NonCommerciall 4.0 International 


\title{
Mid-term results with the Open Chimney technique during Endovascular Aneurysm Repair
}

\author{
E. Ducasse ${ }^{1 *}$, C. Caradu ${ }^{1}$, C. Brochier ${ }^{1}$, D. Midy ${ }^{1}$, X. Bérard ${ }^{1}$, M. Poirier,${ }^{2}$ N.
} Ottaviani $^{1}$

${ }^{1}$ Unit of Vascular Surgery, Pellegrin Hospital, University of Bordeaux, Bordeaux, France

${ }^{2}$ Unit of Vascular Surgery, $\mathrm{CH}$ de Mont-de-Marsan, Mont-de-Marsan, France

* Corresponding author : Eric Ducasse, unit of vascular surgery, université de Bordeaux, CHU de Bordeaux, France, eric.ducasse@chu-bordeaux.fr

\section{Authors' Note}

This study was presented at the $31^{\text {th }}$ annual meeting of the French Society of Vascular and Endovascular Surgery at Toulouse, France, in June 2017.

\section{Declaration of Conflicting Interests}

The author(s) declare no potential conflicts of interest with respect to the research, authorship, and/or publication of this article.

\section{Funding}

The author(s) received no financial support for the research, authorship, and/or publication of this article. 


\section{ABSTRACT}

2

3 Purpose. To report the midterm experience with chimney-endovascular aneurysm

4 repair (Ch-EVAR) with the use of open self-expending stents for branch vessel

5 preservation.

6 Materials and Methods. From July 2010 to May 2017, 67 patients underwent open

7 Ch-EVAR because their proximal landing zones were adjacent to, or covered, the

8 renal or mesenteric arteries (Zones 7-9) and they were not suitable for standard or

9 Fenestrated-EVAR. The proximal landing zone was relocated below the highest renal artery in 46 cases, superior mesenteric artery in 17 and celiac artery in 4 , using 84 open chimneys (131 stents). A subgroup analysis was performed between an early (2010-2014) and a late time period (2015-2017), 32 patients were treated during the early period and 35 during the late period. In the later period, open chimneys were strengthened by a second self-expanding stent.

Results. Primary technical success rate was $89.6 \%$. The early mortality rate was 9.0\%. Median follow-up duration was 13 months (range 1-76 months). The estimated actuarial survival rate was $85.7 \%$ in year 1 and $79.2 \%$ in year 2 and the estimated patency rate of open chimneys reached $95.2 \%$ at 2 years. Aneurysm sac regression $>5 \mathrm{~mm}$ and sac stability rates were $39.0 \%$ and $57.6 \%$ respectively. Freedom from aneurysm-related reintervention was lower in the late period (log-rank $P=.04$ ), while type la endoleaks tended to be twice as likely.

Conclusion. Midterm results of open Ch-EVAR show high technical success with acceptable midterm patency and lack of endoleak in appropriately selected patients. The advantages over covered stents are lower profile delivery systems and 
25 maintenance of branch vessel patency in early bifurcations and overlying visceral 26 vessels.

27 


\section{ABBREVIATIONS}

$29 \mathrm{AAA}=$ abdominal aortic aneurysm, $\mathrm{CE}=$ European Community, $\mathrm{Ch}=$ Chimney, $\mathrm{F}-=$

30 Fenestrated, $\mathrm{CT}=$ computed tomography, EVAR $=$ endovascular aneurysm repair,

31 SESs = self-expanding stents, SMA = Superior mesenteric artery. 
32 Chimney endovascular aneurysm repair (Ch-EVAR) has emerged as an alternative

33 treatment option for abdominal aortic aneurysms (AAAs) with complex anatomy,

34 lacking an adequate infrarenal sealing zone (1). After the early success of bailout

maneuvers for unintentional renal artery coverage (2), parallel grafts have been used as planned repairs to extend the proximal sealing zone, while maintaining side branch patency through covered balloon-expandable stents, covered self-expanding stents (SESs) or bare SESs in the "open" chimney technique $(3,4)$.

Although the Endurant ${ }^{\circledR}$ endograft system (Medtronic Vascular, Santa Rosa, CA, USA) obtained CE-mark approval for Ch-EVAR in 2016, no device has been created solely for this indication with several centers publishing their experience using a variety of devices (5-7).

Before CE-mark approval, an open chimney protocol using SESs was developed for juxtarenal aneurysms with discrepant renal arteries and showed encouraging earlyterm results (3). The purpose of this study was to report the midterm experience with Ch-EVAR with the use of open SESs for branch vessel preservation in patients with AAAs who were not suitable candidates for standard or Fenestrated (F)-EVAR.

\section{MATERIALS AND METHODS}

\section{Study Population}

This study was developed in accordance with the Declaration of Helsinki and received institutional review board approval. All consecutive patients admitted for EVAR between July 2010 and May 2017 were evaluated for inclusion if they had one or more parameters of a hostile neck and if they were not suitable candidates for the only CE-approved fenestrated endograft at the time (Zenith Fenestrated®; Cook Medical, Melbourne, Australia). The new landing zone had to offer parallel-shaped 
57 aortic walls $\geq 10 \mathrm{~mm}$ in length and $\leq 32 \mathrm{~mm}$ in diameter. The inclusion criteria are 58 detailed in Appendix Table 1.

59 In total, 67 patients (56 male) underwent open Ch-EVAR because their proximal

60

61

62

63

64

65

66

67

68

69

70

71

72

73

74

75

76

77

78

79

80

81 landing zones were adjacent to, or covered, the renal or mesenteric arteries (zones 7 through 9 according to the Society for Vascular Surgery classification. Per that classification, zone 7 covers the SMA and ends proximal to renal arteries, zone 8 covers at least one renal artery and zone 9 is infrarenal) (8). Table 1 summarizes patient demographics. Seven patients (10.4\%) presented with acute aortic syndrome but remained hemodynamically stable until surgery. The proximal landing zone was relocated below the highest renal artery in 46 cases, the SMA in 17 cases and the celiac artery in 4 cases, using 84 open chimneys created with 131 SESs. The median length of improved landing-zone was $17 \mathrm{~mm}$ (range $7-26$ ) and the median follow-up duration was 13 months (range 1-76) (early group, 31 [range 6-76], and late group, 8 [range 1-37]). The study was divided into an early period (from 2010 to 2014) and a late period (from 2015 to 2017). The later time period differed by the extent of endovascular repair to more complicated designs and the reinforcement of open chimneys by a second SES (15). Thirty-two patients were treated during the early period and 35 during the late period (Fig 1). There was no significant difference in patients' demographics between the 2 study periods except for a significantly lower number of current smokers during the late period $(P=.048)$.

\section{Procedure Details}

Forty-two procedures were performed at the main study center and 25 at 12 other European vascular centers, where the same team was tutoring for complex aortic repairs. During the study period, 372 EVARs were performed. Device sizing was 
82 provided by the primary surgeon on a dedicated imaging workstation (DxWin $\circledast$ Ver.

83 6.3e14, Medasys Inc, Clamart, France) using high-resolution CT scans. Procedures 84 were performed in the operating room under general anesthesia and systemic heparinization $(0.5 \mathrm{mg} / \mathrm{kg})$ as previously described $(3,9)$. Briefly, the aortic graft was introduced from a femoral access. A bare SES was placed into the target vessel from an upper brachial access over a superstiff 0.035" Rosen wire (CookEurope, Bjaeverskov, Denmark). Chimney grafts were chosen to extend $\geq 1 \mathrm{~cm}$ above the covered part of the aortic graft into the free-flow section, as per the actual instructions for use of the CE-mark approval, and to leave $\geq 2 \mathrm{~cm}$ within the target vessel. The median diameters of the open chimneys were $9 \mathrm{~mm}$ (range, 8-10) and $6 \mathrm{~mm}$ (range, $5-8$ ), with a median length of $60 \mathrm{~mm}$ (range, 40-60) and 40 $\mathrm{mm}$ (range, 20-80) for the superior mesenteric artery (SMA) and the renal arteries, respectively.

Zenith $^{\circledR}$ (Cook Medical, Melbourne, Australia) and Lifestent ${ }^{\circledR}$ (Bard Peripheral Vascular, Tempe, AZ, USA) devices were progressively replaced by Endurant ${ }^{\circledR}$ and Complete $\mathrm{SE}^{\circledR}$ devices (Medtronic, Minneapolis, MN, USA) during the late period. Complete $S E^{\circledR}$ stents were preferred because of enhanced visibility and a triaxial design, which stabilizes the sheath by reducing friction forces, and ultimately leads to an easier and more accurate deployment of the chimney. A significantly greater degree of oversizing was also applied to the aortic graft during the late period $(P=$ $.006)$ in reaction to prior investigations $(9,10)$ to allow the fabric to mold around the chimneys and limit the risk of type la endoleaks (11). After extrinsic compression due to device-to-device and device-to-vessel interaction was reported for 2 patients in the early period of this study and in other studies (15), open chimneys were strengthened by a second SES of the same diameter and length to increase their radial force. The 
endovascular repair was also extended to more complicated designs. Every renal artery or SMA close to the proximal landing zone was considered a target artery and a kissing balloon technique was not used since the implanted stents were only SESs.

\section{Post-Operative Management}

The patients were admitted to the intensive care unit for 0 to 31 days and stayed in the hospital during a median of 7 days (range, 1-372). A subcutaneous adjusteddose of unfractionated heparin was administered to match a plasma heparin level, as expressed by anti-Xa activity, of 0.4 to $0.8 \mathrm{UI} / \mathrm{mL}$ for 48 hours, then patients were treated with dual antiplatelet therapy and statins for 3 months, followed by single antiplatelet therapy in the long term if not otherwise indicated.

In the absence of specific contraindications, follow-up contrast enhanced CT scans were performed before discharge, then at 6 months and 12 months, and yearly thereafter. In addition, a Duplex ultrasound was performed before discharge and serum creatinine levels were monitored before each CT scan.

\section{Outcome Measures}

Procedural and periprocedural factors were assessed, endpoints of this investigation included initial technical success and complications, all-cause mortality, freedom from secondary intervention and endoleak, and the estimated patency rates of open chimneys as well as sac enlargement. Definitions complied with the reporting standard (13). Primary technical success was defined by successful deployment of the devices in the absence of surgical conversion or mortality, type I or III endoleaks, or graft occlusion. An endoleak was defined by the persistence of blood flow outside 
132 the lumen of the endoluminal graft but within the aneurysm sac, as determined by the

133 final angiogram or any of the follow-up CT scans. Additionally, type la endoleaks

134 were further characterized, according to the definition provided by Ullery et al.,

135 into"long" and "short" gutter endoleaks (14). A «hostile abdomen» was defined as an

136 abdomen with persistent loss of natural free spaces between intra-abdominal organs

137 and structures of abdominal compartment, pathological changes of their normal

138 anatomical proportions and adhesions as a consequence of previous laparotomies,

139 peritonitis, pancreatitis, abdominal trauma, intestinal Crohn's disease or extensive

140 radiation therapy.

141

142 Statistical Analysis

143 GraphPad Prism v7.0 (GraphPad Inc, San Diego, Calif) was used for statistical 144 analysis. Data are shown as basic descriptive statistics, such as median (range) or 145 means for continuous variables and proportions and frequencies for categorical 146 variables. A subgroup analysis was performed between an early (from 2010 to 2014)

147 and later time period (from 2015 to 2017). Normality of data was tested with the 148 Shapiro-Wilk test. Differences between groups were evaluated with a contingency 149 table analysis and a $\mathrm{x}^{2}$ test (categorical variables), Mann-Whitney or $\mathrm{t}$ tests 150 (continuous variables) as appropriate. Kaplan-Meier analysis was used to assess 151 midterm follow-up outcomes (survival, freedom from aneurysm-related mortality, 152 reintervention, and target vessel's patency) and comparisons between groups were 153 assessed with the log-rank test. Statistical significance was assumed at $p<.05$. 154

155 RESULTS

156 Initial Technical Success and Complication 
157 Anatomic Characteristics and periprocedural factors are reported in Table 2. Primary

158 technical success rate of open Ch-EVAR was $89.6 \%$ (early group, $93.8 \%$ vs. late 159 group, 85.7\%; $P=.29)$. No procedure-related death or open conversion were 160 reported and every target vessel was successfully reconstructed. The mean ratio of

161

162 163

164

165

166

167

168

169

170

171

172 According to the reporting standard (13), 10 mild, 7 moderate and 7 severe 17

174 175

176 177 178 179 180 181 open chimneys per patient was 1.2 (early group, $1.1 \mathrm{vs.} \mathrm{late} \mathrm{group,} \mathrm{1.4),} \mathrm{which} \mathrm{led} \mathrm{to}$ a significant increase in operating time during the late period (total, 120 [range, 70315]) (early group, 108 [range, 70-290] vs. late group, 164 [range, 81-315]; $P=$ .004). Perioperative successful aneurysm exclusion was achieved in 60 patients (89.6\%). Seven "short" type la endoleaks (early group, 2 [6.3\%] vs. late group, 5 [14.3\%]; $P=.29$ ) and 11 type II endoleaks (16.4\%) (early group, 6 [18.8\%] vs. late group, $5[14.3 \%] ; P=.63)$ were detected at the end of the procedures. The initial CT scan was performed at a median interval of 4 days post Ch-EVAR (range 0-30 days) and open chimneys helped preserve important overlying visceral arteries in 10 cases (14.9\%) and branch divisions in 5 cases (7.5\%) (Table 3$)$.

complications developed in 22 patients (32.8\%) (Table 4). The in-hospital and early postoperative (30-day) mortality rate was $9 \%$ (8.3\% in asymptomatic patients [5/60]) (early group, 4 [12.5\%] and 5 [15.6\%] vs. late group, 2 [5.7\%] and $1[2.9 \%] ; P=.34$ and $P=.07$ respectively). Patients died of heart failure $(n=1)$, myocardial infarction ( $n=2)$, pneumonia $(n=1)$, multiple organ failure $(n=2$, in patients with symptomatic aneurysms) and stroke $(\mathrm{n}=1)$.

\section{Mid-Term Outcomes}

The estimated actuarial survival rate was $85.7 \%$ and $79.2 \%$ at 1 and 2 -year (early 
182 group, $84.4 \%$ and $76.5 \%$ vs. late group, $84.7 \%$; log-rank $P=.53$ ). Six patients died

183 during the follow-up, of heart failure $(n=3)$, pneumonia $(n=2)$ and aneurysm-related

184 cause $(n=1)$. The patient whose death was potentially aneurysm-related was a 74 -

185 year-old male. He was treated in emergency for a ruptured aneurysm with an aorto-

186 enteric fistula and died 2 months after the initial procedure.

187

188 Estimated 2-year primary patency of open chimneys was $95.2 \%$ (early group, $94.1 \%$

189 vs. late group, 95.9\%; log-rank $P=.70$ ) (Fig 2). There were 4 occlusions of open

190 chimneys to the renal arteries. During the early period, one was incidentally

191 discovered 2 days after the initial procedure on the control CT scan in a patient

192 already on dialysis; and one occurred at 1 month in a patient who suddenly suffered

193 from anuria and neurologic degradation after a cardio-embolic event and died in the

194 aftermath. During the late period, two patients manifested by acute flank pain 17

195 days and 1 month after the initial procedure respectively, they both led to a failed

196 attempt to rescue them, leading to a severe deterioration of the renal function and

197 dialysis in the first patient, while the second did not exhibit any long-term

198 consequence.

199

200 Eight renal infarcts were observed over 6 patients (9.0\%) (early group, 5 infarcts/4 201 patients [12.5\%] vs. late group, 3/2 [5.7\%]; $P=.34)$. The patient in the early group, 202 who presented with bilateral renal infarcts, had a "shaggy" distal aorta and the 203 postoperative CT scan showed multiple distal emboli in the territory of both renal and 204 splenic arteries despite a preserved patency of the main branches, his renal function 205 showed significant improvement during follow-up. Two out of 12 patients 206 experiencing acute kidney injury required temporary dialysis (both in the early group) 
and 2 required permanent dialysis (1 in each group [3.1\% vs. $2.9 \%$ ).

208

209

210

211

212

213

214

215

216

217

218

222

223

224

225

226

\section{DISCUSSION \\ DISCUSSION}

228

229

230

231

No statistical difference was observed in outcome measures, except for significantly lower rates of freedom from aneurysm-related reintervention in the late period compared to the early period (log-rank $P=.04$ ) (Table 6), while "short" type la endoleaks tended to be twice as likely. However, the overall number of type $1 \mathrm{~A}$ endoleak did not differ significantly between the two study periods $(P=.87)$. Overall, 8 type $1 \mathrm{~A}$ endoleaks (/52 patients, $15.4 \%)$ vs. 4 (/15 patients; $26.7 \% ; P=.44)$, including 1 "long" gutter endoleak (1.9\%) vs. $3(20.0 \% ; P=.03)$ and 7 "short" gutter endoleaks $(13.5 \%)$ vs. $1(6.7 \% ; P=.67)$, were detected in patients with 1 open chimney vs. patients with 2 or 3 open chimneys, respectively. Two patients exhibited persistent "short" gutter endoleaks and remain under surveillance with a stability of their sac at $78 \mathrm{~mm}$ at 11 month- and $48 \mathrm{~mm}$ at 43 month-follow-up, respectively (16). Type la endoleak outcomes are reported in Table 5. Four type II endoleaks spontaneously disappeared during the early period ( 1 at 3 months, 1 at 4 months, 1 at 11 months and 1 at 16 months) and 2 during the late period ( 1 at 1 month and 1 at 22 months). A sac regression $>5 \mathrm{~mm}$ occurred in $39.0 \%$ of the patients (early group, $12 / 28$ and late group, 11/31) and sac stability occurred in 57.6\% (early group, 14/28 vs. late group, 20/31).

This article describes the mid-term follow-up results of the largest series of Ch-EVAR with the exclusive use of bare SESs for the construction of chimneys. A comparison was drawn between an early and later time period, when the endovascular repair was extended to more complicated designs and open chimneys were reinforced by a 
232 second SES. Importantly, the number of detected "short" type la endoleaks tended to

233 be twice as likely during the late period. This difference could be related to an

234 increase in their detection during the final angiogram, rather than an increase in their

235 number. Nonetheless, the $10.4 \%$ rate of early gutter-related type la endoleak is

236 within the 0 to $37.5 \%$ range noted in previous reports $(10,15,17,18)$. Additionally, a

237 decrease in the rates of late type la endoleak and reintervention were reported for a

238 mean new proximal neck length of $18.7 \pm 6.3 \mathrm{~mm}$ (range $6-58$ ) in the PROTAGORAS

239 study (10), which led to the conclusion that a new proximal landing zone $>15 \mathrm{~mm}$ is

240 necessary to increase the potential for spontaneous gutter thrombosis (18). This

241 corroborates with the use of a median neck length of $17 \mathrm{~mm}$ in this study. Ullery et al.

242 reported a $65.2 \%$ rate of spontaneous resolution of these "gutter" endoleaks within a

243 year, and over a $88 \%$ rate by 18 months (14). For those persisting, coil or polymer

244 embolization $(10,14,15)$ and repeat balloon molding offer encouraging results. During

245 the late period of this study, more aggressive treatments of persisting type la

246 endoleaks through the gutters could explain the significant decrease in freedom from

247 aneurysm-related reintervention, since the majority of secondary reinterventions were

248 chimney- or endoleak-related ( 2 and $7 / 6$ patients, including 4 successful treatments

249 of type la endoleaks). Altogether, this might explain the high rate of aneurysm sac

250 regression or stability in this series (96.6\%) compared to the literature results (> 85\%)

$251(10,20)$. It is, however, important to consider the fact that the transformation of an

252 open chimney into a covered chimney is usually necessary to avoid branch

253 thrombosis and simplify the embolization process. Besides, the secondary

254 cannulation of an open chimney over its entire length might prove difficult depending

255 on its angulation.

256 
257 This study showed a higher rate of open chimneys' occlusions when combined with 258 stainless steel aortic grafts (Zenith ${ }^{\circledR}$ devices) (3 occlusions, 6.4\%), compared to 259 nitinol aortic grafts (Endurant ${ }^{\circledR}$ devices) (1 occlusion secondary to a cardio-embolic 260 event, 3.4\%). Nitinol endoskeletons exhibit more elasticity and exert a continuous

261 and low outward force. Consistently, a sub analysis of the PERICLES registry

262 recently reported a 1.8-fold increase of chimney occlusion in patients treated with 263 stainless steel devices and balloon-expandable covered stents relative to other 264 chimney stents $(\mathrm{HR}, 4.0 ; 95 \% \mathrm{Cl}, 0.85-18.84 ; P=.08)(5)$. Nitinol aortic endografts 265 might be more suited for Ch-EVAR. Furthermore, a device with a suprarenal bare 266 stent fixation helps anchor the chimney graft up against the aortic wall, which could 267 limit the risks of aortic graft migration, parallel-graft horizontalization and branch 268 occlusion (15).

269

270 The use of bare SESs for the construction of chimneys have some undeniable 271 advantages, especially when using new generation stents, which offer higher 272 flexibility and greater stability during release with smaller delivery systems (down to $2734-\mathrm{F}$ for 1 open chimney, 6 to $9-\mathrm{F}$ for 2 ) in comparison with previous generations. 274 These features are of paramount importance, since target arteries are mostly 275 cannulated from an upper limb access, especially in angulated anatomies $(3,9)$ and 276 hostile iliac accesses (21), which led to their acceptance as an alternative in selected 277 elective cases $(15,17)$. This allows for up to 3 open chimneys to be deployed from a 278 low profile single brachial artery access, when the use of the larger diameter covered 279 stents requires an axillary or contralateral access, which may increase the risk of 280 stroke in relation to aortic arch navigation (22). Additionally, bare stents are available 281 in longer lengths than covered balloon-expandable stents. Finally, the position of the 
282 chimneys is hard to anticipate and it can adopt an anterior or posterior helicoidal 283 position (23). Thus, chimneys can sometimes land in front of the ostium of important 284 visceral vessels (Fig 3), where the use of covered stents would have led to their 285 impingement or occlusion. Bare stents offer persisting blood flow through their struts, 286 which could help preserve the patency of close overlying visceral vessels. Likewise, 287 the stent can be pushed further inside the target vessel for safer anchoring without 288 losing the perfusion of any of the branches, even when there is an early bifurcation 289 (i.e. emergence of segmental branches $\leq 2 \mathrm{~cm}$ from origin). Recently, some reports 290 noted a trend toward an increase in type la endoleaks with the use of SESs 291 compared to balloon-expandable stents $(15,16)$. However, these may be the result of 292 selection bias, since SESs were mostly reserved for cases with excessive branch 293 vessel angulation.

294 Finally, the patency rates of these open chimneys (95.2\% for a mean imaging follow295 up of 19.3 months) are comparable to the ones previously reported in the 296 PROTAGORAS study, which analyzed the combination of the Endurant ${ }^{\circledR}$ graft with 297 covered balloon-expandable stents, and concluded to a primary patency rate of 298 $95.7 \%$ (8 occluded chimneys) for a mean follow-up duration of 24.6 months (17). This supports the theory that the covered nature of the stent does not confer any benefit in 300 terms of patency in this indication (17). Additionally, the PROTAGORAS study 301 reported a $93.1 \%$ rate of freedom from chimney graft-related reintervention, which 302 compares favorably to the $97.6 \%$ rate of this series ( 2 chimney graft-related 303 reinterventions). Importantly, 30-day mortality was high compared to other series $304(13,17)$, but might be partially explained by a larger number of patients with coronary 305 artery disease and unfavorable anatomies compared to standard or F-EVAR series. 306 Nonetheless, all-cause mortality was $19.4 \%$ (no late aortic rupture), which compares 
307 well to the $17.2 \%$ reported in the PROTAGORAS study (1 procedure-related late 308 aortic rupture).

309 The number of patients included in this study remains low, which could have led to 310 insufficient statistical power. Thus, this study could not demonstrate a definite 311 advantage in the use of a second SES to reinforce the open chimney and this point 312 will truly deserve further investigations in order to determine if this could help 313 preserve the patency of the chimneys, as advocated by some literature results $314(11,15)$.

315 Finally, because the alternatives to Ch-EVAR in the elective setting could offer more 316 durable outcomes, selection criteria should remain strict and no compromise should 317 be made on the sealing area.

318 In conclusion, midterm results of open Ch-EVAR show high technical success with 319 acceptable midterm patency and lack of endoleak in appropriately selected patients.

320 The advantages over more recently introduced covered stents for this purpose are 321 lower profile delivery systems (potentially reducing complications relative to upper 322 limb access) and maintenance of branch vessel patency in early bifurcations and 323 overlying visceral vessels. Nonetheless, the reintervention rates remain high and 324 long-term follow-up will determine the durability of this approach. 
326 1. Patel RP, Katsargyris A, Verhoeven ELG, Adam DJ, Hardman JA.

327 Endovascular aortic aneurysm repair with chimney and snorkel grafts: indications,

328 techniques and results. Cardiovasc Intervent Radiol. 2013 Dec;36(6):1443-51.

329 2. Greenberg RK, Clair D, Srivastava S, Bhandari G, Turc A, Hampton J, et al.

330 Should patients with challenging anatomy be offered endovascular aneurysm repair?

331 J Vasc Surg. 2003 Nov;38(5):990-6.

332 3. Ducasse E, Lepidi S, Brochier C, Deglise S, Berard X, Alberti D, et al. The

333 'open' chimney graft technique for juxtarenal aortic aneurysms with discrepant renal 30

4. Lachat M, Veith FJ, Pfammatter T, Glenck M, Bettex D, Mayer D, et al. Chimney and periscope grafts observed over 2 years after their use to revascularize 169 renovisceral branches in 77 patients with complex aortic aneurysms. J Endovasc Ther Off J Int Soc Endovasc Spec. 2013 Oct;20(5):597-605.

5. Scali ST, Beck AW, Torsello G, Lachat M, Kubilis P, Veith FJ, et al. Identification of optimal device combinations for the chimney endovascular aneurysm repair technique within the PERICLES registry. J Vasc Surg. 2018 Jan 27;

6. Mestres G, Uribe JP, García-Madrid C, Miret E, Alomar X, Burrell M, et al. The best conditions for parallel stenting during EVAR: an in vitro study. Eur J Vasc Endovasc Surg Off J Eur Soc Vasc Surg. 2012 Nov;44(5):468-73.

7. Lachat M, Bisdas T, Rancic Z, Torsello G, Mayer D, Gil-Sales J, et al. Chimney endografting for pararenal aortic pathologies using transfemoral access and the lift technique. J Endovasc Ther Off J Int Soc Endovasc Spec. 2013 Aug;20(4):492-7.

8. Fillinger MF, Greenberg RK, McKinsey JF, Chaikof EL, Society for Vascular Surgery Ad Hoc Committee on TEVAR Reporting Standards. Reporting standards for thoracic endovascular aortic repair (TEVAR). J Vasc Surg. 2010 Oct;52(4):1022-33, 1033.e15.

9. Caradu C, Morin J, Poirier M, Midy D, Ducasse E. Monocentric evaluation of chimney versus fenestrated endovascular aortic repair for juxta-renal abdominal aortic aneurysm. Ann Vasc Surg. 2017 Feb 1;

10. Donas KP, Torsello GB, Piccoli G, Pitoulias GA, Torsello GF, Bisdas T, et al. The PROTAGORAS study to evaluate the performance of the Endurant stent graft for patients with pararenal pathologic processes treated by the chimney/snorkel endovascular technique. J Vasc Surg. 2016 Jan;63(1):1-7.

11. Mestres G, Yugueros X, Apodaka A, Urrea R, Pasquadibisceglie S, Alomar X, et al. The best in vitro conditions for two and three parallel stenting during endovascular aneurysm repair. J Vasc Surg. 2017 Oct;66(4):1227-35.

12. Voskresensky I, Scali S, Feezor RJ, Fatima J, Giles KA, Tricarico R, et al. Outcomes of Thoracic Endovascular Aortic Repair Using Aortic Arch Chimney Stents in High Risk Patients. J Vasc Surg. 2017 Jul;66(1):9-20.e3.

13. Chaikof EL, Blankensteijn JD, Harris PL, White GH, Zarins CK, Bernhard VM, et al. Reporting standards for endovascular aortic aneurysm repair. J Vasc Surg. 2002 May 1;35(5):1048-60.

14. Ullery BW, Tran K, Itoga NK, Dalman RL, Lee JT. Natural history of gutterrelated type la endoleaks after snorkel/chimney endovascular aneurysm repair. J Vasc Surg. 2017 Apr;65(4):981-90.

15. Donas KP, Lee JT, Lachat M, Torsello G, Veith FJ, PERICLES investigators. 
374 Collected world experience about the performance of the snorkel/chimney

375 endovascular technique in the treatment of complex aortic pathologies: the

376 PERICLES registry. Ann Surg. 2015 Sep;262(3):546-53; discussion 552-553.

377 16. Donas KP, Pecoraro F, Torsello G, Lachat M, Austermann M, Mayer D, et al.

378 Use of covered chimney stents for pararenal aortic pathologies is safe and feasible

379 with excellent patency and low incidence of endoleaks. J Vasc Surg. 2012

380 Mar;55(3):659-65.

381 17. Hiramoto JS, Chang CK, Reilly LM, Schneider DB, Rapp JH, Chuter TAM.

382 Outcome of renal stenting for renal artery coverage during endovascular aortic

383 aneurysm repair. J Vasc Surg. 2009 May 1;49(5):1100-6.

384 18. Moulakakis KG, Mylonas SN, Avgerinos E, Papapetrou A, Kakisis JD,

385 Brountzos EN, et al. The chimney graft technique for preserving visceral vessels

386

387

388

389

390

391

392

393

394

395

396

397

398

399

400

401

402

403

404

405 during endovascular treatment of aortic pathologies. J Vasc Surg. 2012 May;55(5):1497-503.

19. Donselaar EJ, van der Vijver-Coppen RJ, van den Ham LH, Lardenoye JWHP, Reijnen MMPJ. EndoAnchors to Resolve Persistent Type la Endoleak Secondary to Proximal Cuff With Parallel Graft Placement. J Endovasc Ther. 2016 Feb 1;23(1):225-8.

20. Donas KP, Pecoraro F, Bisdas T, Lachat M, Torsello G, Rancic Z, et al. CT angiography at 24 months demonstrates durability of EVAR with the use of chimney grafts for pararenal aortic pathologies. J Endovasc Ther Off J Int Soc Endovasc Spec. 2013 Feb;20(1):1-6.

21. Caradu C, Bérard X, Midy D, Ducasse E. Influence of Anatomic Angulations in Chimney and Fenestrated Endovascular Aneurysm Repair. Ann Vasc Surg. 2017 Feb 28;

22. Cui X, Li Y, Liu J, He S, Liu M. Aortic arch atheroma and the risk of stroke: a meta-analysis. J Evid-Based Med. 2014 Aug;7(3):185-91.

23. Tran K, Ullery BW, Itoga N, Lee JT. Polar orientation of renal grafts within the proximal seal zone affects risk of early type la endoleaks after chimney endovascular aneurysm repair. J Vasc Surg [Internet]. 2017 Oct 23 [cited 2018 Feb 28];0(0).

Available from: http://www.jvascsurg.org/article/S0741-5214(17)32103-1/fulltext 


\section{Figure 1. Flow Chart}

408

409 Covered arteries (X)

410 Open chimneys (arrowheads)

411

412 Figure 2. Kaplan-Meier curves. (a) Overall survival. (b) Freedom from aneurysm-

413 related reintervention. (c)(d) Subgroup analysis between an early and later time

414 period (early period : from 2010 to 2014 and late period : from 2015 to 2017, when

415 chimney grafts were reinforced by a second self-expanding stent). (c) Overall

416 survival. (d) Freedom from aneurysm-related reintervention. (e) Aneurysm sac

417 evolution relative to the maximum transverse diameter (Aneurysm enlarged $>5 \mathrm{~mm}$

418 between two CT scan measures in 2 patients (3.0\%), remained stable with variations

419 between -5 and $5 \mathrm{~mm}$ in 34 patients (50.7\%) and decreased $>5 \mathrm{~mm}$ in 23 patients $420(34.3 \%))$.

421

$422 \quad F U=$ Follow-up.

423

424 Figure 3. Images from patients with AAA treated with open chimneys. (a) Images 425 from a 77-year-old male patient with a AAA treated with an open chimney to the left 426 renal artery. The contrast-enhanced CT scan obtained 2 years after the procedure 427 shows the traditional conformation of the chimney graft, the aortic endograft and the 428 aortic wall, leaving only a small "physiologic" blind gutter space. (b)(c) Images from 429 an 80-year old male patient treated with open chimneys to both renal arteries. (b) 430 The contrast-enhanced CT scan obtained 2 years after the procedure shows the 431 positioning of the upper part of both open chimneys in front of the ostium of the 
432 superior mesenteric artery. Both renal arteries and the superior mesenteric artery

433 remain patent. (c) Three D reconstruction confirms the positioning of the stents in

434 front of the superior mesenteric artery, and the preserved patency of the renal

435 arteries and the superior mesenteric artery. $(\mathbf{d})(\mathbf{e})(\mathbf{f})(\mathbf{g})$ Images from a patient with a

436 history of prior infra-renal endovascular reconstruction treated with open chimneys to

437 both renal arteries to correct a type la endoleak during the late period. (d) Immediate

438 post-operative contrast-enhanced CT scan shows the persistence of a type la

439 endoleak (arrowhead) after the open chimney procedure. (e) MIP of the immediate

440 post-operative contrast-enhanced CT scan shows a "long" gutter endoleak

441 (arrowhead) relative to the left renal artery's gutter, going into the aneurysm sac. (f)

442 Angiogram obtained during a secondary procedure confirms the localization of the

443 type la endoleak (arrowhead). (g) Angiogram obtained 16 months after the

444 embolization procedure shows the absence of any residual type la endoleak through

445 the gutter.

446

$447 \quad$ AAA $=$ abdominal aortic aneurysm; MIP = Maximum Intensity Projection

448 


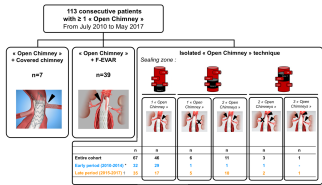

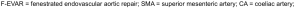
RRA = niph sens artery: LRA = left rend srter

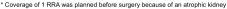

T Coverage of 3 URA and 1 RRA wes plwned behre surgery because of atrophis kidrense in 2 cases. and

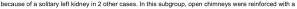
socond sathevpanding shen 
a.

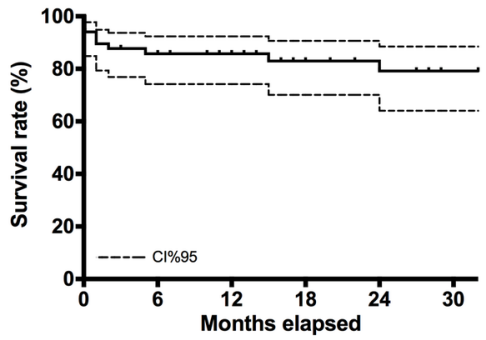

- Entire cohort

\begin{tabular}{lllllll} 
\# at risk & 67 & 42 & 35 & 26 & 22 & 17 \\
\% survival & 100.0 & 85.7 & 85.7 & 83.0 & 79.2 & 79.2 \\
\hline
\end{tabular} b.

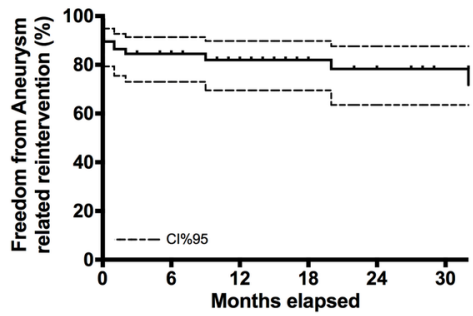

- Entire cohort

$\begin{array}{lllllll}\text { \# at risk } & 67 & 39 & 31 & 24 & 19 & 14 \\ \text { \% survival } & 100.0 & 84.5 & 82.0 & 82.0 & 78.3 & 78.3\end{array}$ $\begin{array}{llllllll} & \mathrm{Cl} \% 95 & - & 73.0-91.4 & 69.5-89.7 & 69.5-89.7 & 63.5-87.6 & 63.5-87.6\end{array}$ c.

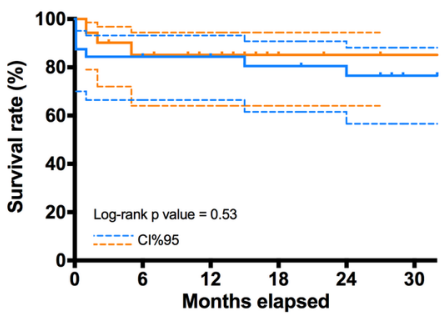

- Early period (2010-2014)

$\begin{array}{lllllll}\text { \# at risk } & 32 & 26 & 23 & 22 & 20 & 16 \\ \text { \% survival } & 100.0 & 84.4 & 84.4 & 80.5 & 76.5 & 76.5\end{array}$

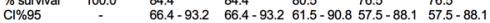

- Late period (2015-2017)

$\begin{array}{lllllll}\text { \# at risk } & 35 & 18 & 13 & 5 & 3 & 2 \\ \text { \% survival } & 100.0 & 84.7 & 84.7 & 84.7 & 84.7 & 84.7\end{array}$

$\begin{array}{lcccccc}\text { Cl\%95 } & - & 62.9-94.2 & 62.9-94.2 & 62.9-94.2 & 62.9-94.2 & 62.9-94.2\end{array}$ d.

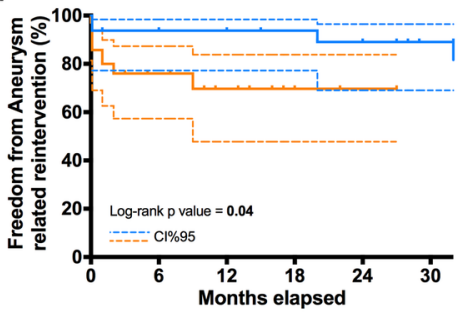

- Early period (2010-2014)

$\begin{array}{lllllll}\text { \# at risk } & 32 & 25 & 22 & 21 & 18 & 14 \\ \text { \% survival } & 100.0 & 93.8 & 93.8 & 93.8 & 89.1 & 89.1\end{array}$

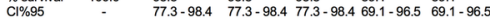

- Late period (2015-2017)

$\begin{array}{lllllll}\text { \# at risk } & 35 & 16 & 10 & 4 & 2 & 1 \\ \text { \% survival } & 100.0 & 76.0 & 69.7 & 69.7 & 69.7 & 69.7\end{array}$ $\begin{array}{lclllll}\text { \% survival } & 100.0 & 76.0 & 69.7 & 69.7 & 69.7 & 69.7 \\ \text { Cl\%95 } & - & 57.3-87.3 & 47.8-83.8 & 47.8-83.8 & 47.8-83.8 & 47.8-83.8\end{array}$

e.

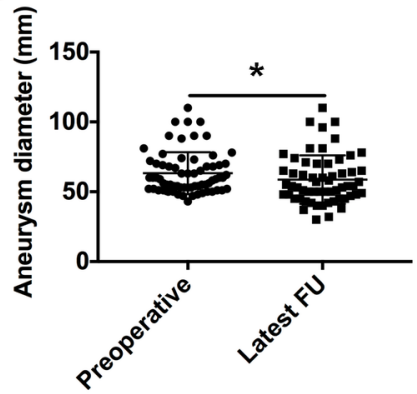

$\begin{array}{lcc}\text { \# at risk } & 67 & 59 \\ \text { Median } & 59 & 54 \\ \text { Range } & 43-110 & 30-110\end{array}$




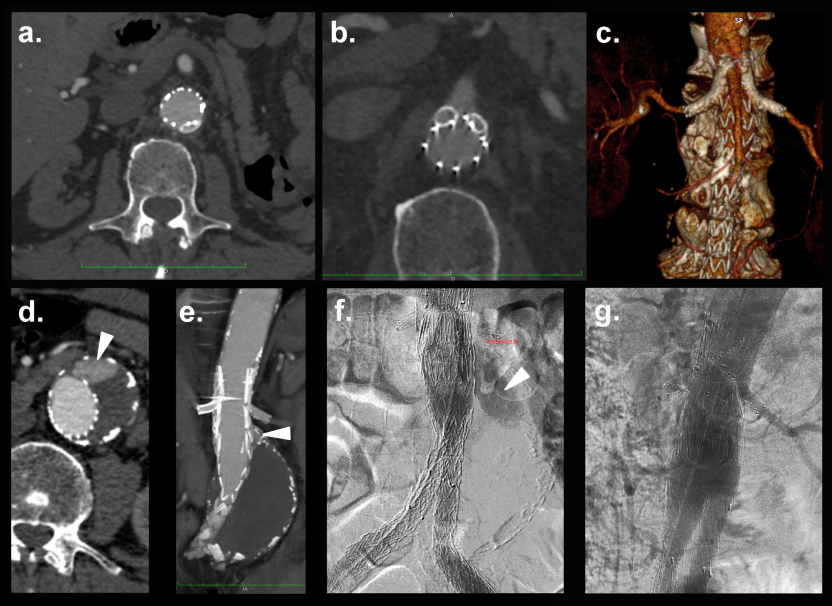




\section{Table 1. Patient Characteristics and Demographics}

\begin{tabular}{|c|c|c|c|c|}
\hline Characteristic & $\begin{array}{l}\text { Total } \\
(n=67)\end{array}$ & $\begin{array}{l}\text { Early period } \\
(2010-2014) \\
(n=32)\end{array}$ & $\begin{array}{l}\text { Late period } \\
(2015-2017) \\
(n=35)\end{array}$ & $P$ Value $^{\star}$ \\
\hline Age, yr & $77(62-88)$ & $76(63-88)$ & $80(62-88)$ & 17 \\
\hline Male & $56(83.6 \%)$ & $27(84.4 \%)$ & $29(82.9 \%)$ & .87 \\
\hline $\begin{array}{l}\text { ASA class } \\
\text { III } \\
\text { IV }\end{array}$ & $\begin{array}{l}43(64.2 \%) \\
4(6.0 \%)\end{array}$ & $\begin{array}{l}20(62.5 \%) \\
5(15.6 \%)\end{array}$ & $\begin{array}{l}23(65.7 \%) \\
5(14.3 \%)\end{array}$ & .97 \\
\hline $\begin{array}{l}\text { Diabetes } \\
\text { CAD } \\
\text { COPD } \\
\text { Current smoker } \\
\text { Preoperative renal disease }\end{array}$ & $\begin{array}{l}8(11.9 \%) \\
37(55.2 \%) \\
19(28.4 \%) \\
19(28.4 \%) \\
27(40.3 \%)\end{array}$ & $\begin{array}{l}4(12.5 \%) \\
20(62.5 \%) \\
8(25.0 \%) \\
13(40.6 \%) \\
15(46.9 \%)\end{array}$ & $\begin{array}{l}4(11.4 \%) \\
17(48.6 \%) \\
11(31.4 \%) \\
6(17.1 \%) \\
12(34.3 \%)\end{array}$ & $\begin{array}{l}.96 \\
.38 \\
.47 \\
.048 \\
.30\end{array}$ \\
\hline Hostile abdomen & $12(17.9 \%)$ & $4(12.5 \%)$ & $8(22.9 \%)$ & .23 \\
\hline $\begin{array}{l}\text { Prior aortic surgery } \\
\text { Type la EL from prior EVAR } \\
\text { Para-anastomotic aneurysm } \\
\text { Thoracic endograft }\end{array}$ & $\begin{array}{l}8(11.9 \%) \\
4(6.0 \%) \\
2(3.0 \%) \\
2(3.0 \%)\end{array}$ & $\begin{array}{l}3(9.4 \%) \\
0(0.0 \%) \\
1(3.1 \%) \\
2(6.3 \%)\end{array}$ & $\begin{array}{l}5(14.3 \%) \\
4(11.4 \%) \\
1(2.9 \%) \\
0(0.0 \%)\end{array}$ & .54 \\
\hline \multicolumn{5}{|l|}{ Clinical status } \\
\hline Symptomatic $^{\dagger}$ & $7(10.4 \%)$ & $4(12.5 \%)$ & $4(11.4 \%)$ & .96 \\
\hline Penetrating ulcer & $6(9.0 \%)$ & $2(6.3 \%)$ & $4(11.4 \%)$ & .47 \\
\hline Rapidly growing or $\theta \geq 70 \mathrm{~mm}$ & $15(22.4 \%)$ & $8(25.0 \%)$ & $7(20.0 \%)$ & .63 \\
\hline
\end{tabular}

All values with ranges are median (range).

$\mathrm{ASA}=$ american society of anesthesiologists; $\mathrm{CAD}=$ coronary artery disease; COPD = chronic obstructive pulmonary disease; $\mathrm{BMI}=$ body mass index; $\mathrm{EL}=$ Endoleak; EVAR $=$ endovascular aortic repair; $\theta=$ Maximum Transverse Diameter.

* the $p$ values refer to the comparison between the two study periods.

$\dagger$ acute aortic syndrome with either painful aneurysms with stable patients at admission or contained ruptures on Computed Tomographic Angiography. 
Table 2. Anatomic Characteristics and periprocedural factors

\begin{tabular}{|c|c|c|c|c|}
\hline Characteristic & Entire Cohort & $\begin{array}{l}\text { Early period } \\
(2010-2014)\end{array}$ & $\begin{array}{l}\text { Late period } \\
(2015-2017)\end{array}$ & $P$ value ${ }^{\star}$ \\
\hline \multicolumn{5}{|l|}{ Aortic anatomy, mm } \\
\hline Maximum aneurysm diameter & $59(43-110)$ & $60(43-110)$ & $59(47-110)$ & .46 \\
\hline Infrarenal neck length & $3(0-16)$ & $4(0-16)^{\dagger}$ & $3(0-16)^{\dagger}$ & .89 \\
\hline Length of New sealing zone & $17(7-26)$ & $18(7-26)$ & $14(10-24)$ & .63 \\
\hline \multicolumn{5}{|l|}{ Aortic graft } \\
\hline Zenith $^{(B)}$ (Cook) & $39(58.2 \%)$ & $27(84.4 \%)$ & $12(34.3 \%)$ & $<.0001$ \\
\hline Endurant ${ }^{(\Theta)}$ (Medtronic) & $22(32.8 \%)$ & $4(12.5 \%)$ & $18(51.4 \%)$ & .0005 \\
\hline $\mathrm{AFX}^{(B)}$ (Endologix) & $1(1.5 \%)$ & $1(3.1 \%)$ & $0(0.0 \%)$ & \\
\hline $\mathrm{C}^{(B)}$ (Gore) & $5(7.5 \%)$ & $0(0.0 \%)$ & $5(14.3 \%)$ & \\
\hline Oversizing, \% & $19(13-33)$ & $17(13-28)$ & $22(13-33)$ & .006 \\
\hline Aorto-biiliac graft & $58(86.6)$ & $28(87.5 \%)$ & $30(85.7 \%)$ & .83 \\
\hline Aorto-mono iliac graft+femoro-femoral bypass & $4(6.0 \%)$ & $3(9.4 \%)$ & $1(2.9 \%)$ & .27 \\
\hline Proximal Cuff & $5(7.5 \%)$ & $1(3.1 \%)$ & $4(11.4 \%)$ & .20 \\
\hline Hypogastric artery embolization & $8(11.9 \%)$ & $5(15.6 \%)^{\ddagger}$ & $3(8.6 \%)$ & .38 \\
\hline Number of Target vessels & $83(100 \%)$ & $34(100 \%)^{\S}$ & $49(100 \%)$ ** & \\
\hline SMA & $4(4.8 \%)$ & $1(2.9 \%)$ & $3(6.1 \%)$ & \\
\hline Left renal artery & $53(63.9 \%)$ & $25(73.5 \%)$ & $28(57.1 \%)$ & \\
\hline Right renal artery & $26(31.3 \%)$ & $8(23.5 \%)$ & $18(36.7 \%)$ & \\
\hline \multicolumn{5}{|l|}{ Chimney grafts } \\
\hline Complete SE ${ }^{(\otimes)}$ (Medtronic) & $28(33.7 \%)$ & $3(8.8 \%)$ & $25(51 \%)^{\dagger \dagger}$ & $<.0001$ \\
\hline Lifestent ${ }^{(B)}$ (Bard) & $23(27.7 \%)$ & $16(47.1 \%)$ & $7(14.3 \%)^{\dagger \dagger}$ & .004 \\
\hline Absolute Pro ${ }^{(}$(Abbott) & $16(19.3 \%)$ & $5(14.7 \%)$ & $11(22.4 \%)^{\dagger \dagger}$ & .13 \\
\hline Astron Pulsar ${ }^{(B)}$ (Biotronik) & $7(8.4 \%)$ & $4(11.8 \%)$ & $3(6.1 \%)^{\dagger \dagger}$ & .61 \\
\hline Protégé EverFlex ${ }^{(B)}$ & $3(3.6 \%)$ & $1(2.9 \%)$ & $2(4.1 \%)^{\dagger \dagger}$ & 62 \\
\hline Epic $^{(B)}$ (Boston Scientific) & $2(2.4 \%)$ & $2(5.9 \%)$ & $0(0.0 \%)$ & \\
\hline Zilver $^{(B)}$ (Cook) & $1(1.2 \%)$ & $0(0.0 \%)$ & $1(2 \%)$ & \\
\hline Luminexx ${ }^{(B)}$ (Bard) & $1(1.2 \%)$ & $1(2.9 \%)$ & $0(0.0 \%)$ & \\
\hline Misago $^{(B)}$ (Terumo) & $1(1.2 \%)$ & $1(2.9 \%)$ & $0(0.0 \%)$ & \\
\hline S.M.A.R.T ${ }^{(B)}$ (Cordis) & $1(1.2 \%)$ & $1(2.9 \%)$ & $0(0.0 \%)$ & \\
\hline \multicolumn{5}{|l|}{ Chimney Access } \\
\hline Right and Left brachial arteries & $6(9 \%)$ & $1(3.1 \%)$ & $5(14.3 \%)$ & \\
\hline Left brachial artery & $61(91 \%)$ & $31(96.9 \%)$ & $30(85.7 \%)$ & .11 \\
\hline \multicolumn{5}{|l|}{ Periprocedural factors } \\
\hline Fluoroscopy time, $\min$ & $37(17-91)$ & $34(15-90)$ & $43(23-91)$ & .22 \\
\hline Kerma area product, Gy/cm² & $110(25-227)$ & $110(29-185)$ & $116(25-227)$ & .76 \\
\hline Contrast volume, $\mathrm{mL}$ & $95(45-180)$ & $99(45-180)$ & $95(45-150)$ & .50 \\
\hline
\end{tabular}

All values with ranges are median (range).

SMA = superior mesenteric artery; ICU = intensive care unit.

* the $p$ values refer to the comparison between the two study periods.

$\dagger$ one patient presented an inverted tapered neck of $16 \mathrm{~mm}$

$\$ 1$ bilateral (right side was treated 3 months before EVAR).

${ }^{\S}$ Coverage of 1 right renal artery was chosen to be performed pre-operatively because of atrophic kidney

** Coverage of 3 left and 1 right renal artery was chosen to be performed pre-operatively because of atrophic kidneys and two patients already presented with a solitary left kidney.

In accordance with the SVS consensus, only renal arteries $<4 \mathrm{~mm}$ in diameter and supporting $<1 / 3$ of renal parenchyma were considered for ostium coverage.

${ }^{\dagger}$ During the late study period chimney grafts were always reinforced with a second self-expanding stent of the same brand, diameter and length, to ease comparison with the early study period only one stent was reported for each target vessel. 


\section{Table 3. Open chimneys and preservation of important branch vessels}

\begin{tabular}{llll}
\hline & Target vessel of the open chimney & Branch vessel at risk $^{*}$ & $\begin{array}{l}\text { Patients } \\
(\mathbf{n}=\mathbf{3 0})\end{array}$ \\
Ostium & & & $10(14.9 \%)$ \\
& SMA & Coeliac Trunk & $2(3.0 \%)$ \\
& Right Renal Artery & SMA and Coeliac Trunk & $1(1.5 \%)$ \\
& Left and Right Renal Arteries & SMA and Coeliac Trunk & $1(1.5 \%)$ \\
& Left Renal Artery & SMA & $3(4.5 \%)$ \\
& Left and Right Renal Arteries & SMA & $2(3.0 \%)$ \\
& Right Renal Artery & Left Renal Artery & $1(1.5 \%)$ \\
Branch Division & & $5(7.5 \%)$ \\
& & & $1(1.5 \%)$ \\
& SMA & & $4(6.0 \%)$ \\
\hline
\end{tabular}

SMA = superior mesenteric artery.

* Branch vessel in front of which the open chimney landed after deployment, in a configuration that would have resulted in a significant stenosis or occlusion of the branch if the stent used for the construction of the chimney had been a covered stent.

At latest follow-up all the branch vessels were still preserved. 
Table 4. Early (30-day) complications

\begin{tabular}{llll}
\hline Characteristic & Total & $\begin{array}{l}\text { Early period } \\
\mathbf{2 0 1 0 - 2 0 1 4 )} \\
\mathbf{( n = 3 2 )}\end{array}$ & $\begin{array}{l}\text { Late period } \\
\mathbf{( 2 0 1 5 - 2 0 1 7 )} \\
\mathbf{( n = 3 5 )}\end{array}$ \\
Mild & $\mathbf{( n = 6 7 )}$ & $4(12.5 \%)$ & $6(17.1 \%)$ \\
access-site hematomas & $10(14.9 \%)$ & $1(3.1 \%)$ & $5(14.3 \%)$ \\
femoral dissection & $6(9.0 \%)$ & $1(3.1 \%)$ & $0(0.0 \%)$ \\
false-aneurysms & $1(1.5 \%)$ & $1(3.1 \%)$ & $0(0.0 \%)$ \\
lymphoceles & $1(1.5 \%)$ & $1(3.1 \%)$ & $1(2.9 \%)$ \\
Moderate & $2(3.0 \%)$ & $4(12.5 \%)$ & $3(8.6 \%)$ \\
false-aneurysms & $7(10.4 \%)$ & $0(0.0 \%)$ & $1(2.9 \%)$ \\
buttock claudication & $1(1.5 \%)$ & $1(3.1 \%)$ & $0(0.0 \%)$ \\
iliac limb occlusion & $1(1.5 \%)$ & $1(3.1 \%)$ & $0(0.0 \%)$ \\
iliac rupture & $1(1.5 \%)$ & $0(0.0 \%)$ & $1(2.9 \%)$ \\
pneumonia & $1(1.5 \%)$ & $2(6.3 \%)$ & $1(2.9 \%)$ \\
Severe & $3(3.6 \%)$ & $6(18.8 \%)$ & $1(2.9 \%)$ \\
iliac limb occlusion & $7(10.4 \%)$ & $2(6.3 \%)$ & $0(0.0 \%)$ \\
iliac rupture & $2(3.0 \%)$ & $1(3.1 \%)$ & $0(0.0 \%)$ \\
pneumonia & $1(1.5 \%)$ & $1(9.4 \%)$ & $0(0.0 \%)$ \\
embolic stroke & $1(1.5 \%)$ & $2(6.3 \%)$ & $1(2.9 \%)$ \\
30- day Mortality & $3(3.6 \%)$ & $5(15.6 \%)$ & $1(2.9 \%)$ \\
\hline
\end{tabular}

* patient required reintervention

$\dagger$ patient presented with progressive pain in the right gluteus, which progressed into rhabdomyolysis and acute renal failure, after a planned occlusion of the right internal iliac for common iliac aneurysm. His serum creatinine levels almost went back to the preoperative values during follow-up and he was left suffering from moderate right buttock claudication.

$\$$ secondary to a kink of the common and external iliac arteries following endograft positioning, and successfully treated by thrombectomy and uncovered stent delivery

$\S$ treated by covered stenting

** related to the upper approach

t† related to cardiac embolism 


\section{Table 5. Overview of type la Endoleak Outcomes}

\begin{tabular}{|c|c|c|c|c|}
\hline Patient & First appearance & Imaging aspect & Open Chimney & Last control \\
\hline \multicolumn{5}{|c|}{ Early period (2010-2014) } \\
\hline 6 & 40 month FU & "Short" gutter endoleak & 1 & Sealed spontaneously at 40 months \\
\hline 7 & 40 month FU & "Short" gutter endoleak & 1 & $\begin{array}{l}\text { Present until death from septic shock over } \\
\text { pneumonia }\end{array}$ \\
\hline 13 & Control angiogram & "Short" gutter endoleak & 1 & Sealed spontaneously at 11 months \\
\hline 18 & 18 month FU & "Long" gutter endoleak & 1 & Sealed after embolization at 48 months \\
\hline 26 & Control angiogram & "Short" gutter endoleak & 1 & Still present (sac stability at 43 months) \\
\hline 29 & 32 month FU & "Long" gutter endoleak & 2 & $\begin{array}{l}\text { Programmed for "neck lengthening" by cuff } \\
\text { addition and transformation of the Open } \\
\text { Chimney into a covered chimney graft }\end{array}$ \\
\hline \multicolumn{5}{|c|}{ Late period $(2015-2017)$} \\
\hline 1 & 1 month FU & "Short" gutter endoleak & 2 & $\begin{array}{l}\text { Present until death secondary to aorto- } \\
\text { digestive fistula }\end{array}$ \\
\hline 6 & Control angiogram & "Short" gutter endoleak & 1 & Present until death from cardiac arrhythmia \\
\hline 7 & Control angiogram & "Short" gutter endoleak & 1 & Still present (sac stability at 11 months) \\
\hline 11 & Control angiogram & "Long" gutter endoleak & 2 & Sealed after embolization at 16 months \\
\hline 12 & Control angiogram & "Long" gutter endoleak & 2 & Sealed after endo-anchoring at 2 months \\
\hline 34 & Control angiogram & "Short" gutter endoleak & 1 & Sealed spontaneously at 3 months \\
\hline
\end{tabular}

$\mathrm{FU}=$ follow-up.

"short" gutter endoleaks : confined to the perigraft channel or those terminating within $10 \mathrm{~mm}$ of the most inferior chimney stent and not associated with aneurysm sac perfusion.

"long" gutter endoleaks : extending $>10 \mathrm{~mm}$ below the most inferior chimney stent and/or extending into the aneurysm sac. 


\section{Table 6. Aneurysm-related reinterventions}

\begin{tabular}{|c|c|c|c|}
\hline Characteristic & Total & $\begin{array}{l}\text { Early period } \\
(2010-2014)\end{array}$ & $\begin{array}{l}\text { Late period } \\
(2015-2017)\end{array}$ \\
\hline Endovascular repair & 23 & 15 & 8 \\
\hline Endoleaks & 10 & 7 & 3 \\
\hline Type la & 4 & 2 * & $2^{\dagger}$ \\
\hline Type lb & 2 & $1^{\ddagger}$ & $1^{\ddagger}$ \\
\hline Prevention of Type lb & 3 & $3^{\S}$ & 0 \\
\hline Type III & 1 & 1 ** & 0 \\
\hline Iliac rupture & 1 & 1 & 0 \\
\hline Occluded Open chimneys & 2 & 0 & $2^{\dagger \dagger}$ \\
\hline $\begin{array}{l}\text { Open surgery } \\
\text { lliac limb occlusion }\end{array}$ & $\begin{array}{l}5 \\
2\end{array}$ & $\begin{array}{l}2 \\
2\end{array}$ & $\begin{array}{l}3 \\
0\end{array}$ \\
\hline Femoral false-aneurysm & 2 & 0 & 2 \\
\hline Hemostatic Nephrectomy & 1 & 0 & 1 \\
\hline \multicolumn{4}{|c|}{ *Embolization } \\
\hline \multicolumn{4}{|c|}{1 Embolization and 1 Endo-anchoring } \\
\hline \multicolumn{4}{|c|}{ Hypogastric embolization and iliac extension } \\
\hline \multirow{2}{*}{\multicolumn{4}{|c|}{$\begin{array}{l}{ }_{3} \text { procedures/2 patients with aneurysmal degeneration of the common iliac arteries } \\
{ }^{* *} \text { Addition of a covered stent between limb modules }\end{array}$}} \\
\hline & & & \\
\hline \multicolumn{4}{|c|}{ †† Unsuccessful } \\
\hline \multicolumn{4}{|c|}{$\$ 1$ thrombectomy + stenting and 1 femoro-femoral bypass } \\
\hline
\end{tabular}

